\title{
COVID-19 front door screening implementation: experiences of staff conducting screening
}

\author{
AUTHORS \\ KATE KENNEDY GCert PubHlth ${ }^{1}$ \\ JENNIFER A FISH PhD ${ }^{1}$ \\ DEBORAH FORSYTHE BOccThy ${ }^{1}$ \\ IMOGEN J RAMSEY BPsych ${ }^{1}$ \\ PAMELA ADELSON MPH ${ }^{1}$
}

\section{CORRESPONDING AUTHOR}

KATE KENNEDY Rosemary Bryant AO Research Centre, UniSA Clinical \& Health Sciences, University of South Australia, GPO Box 2471 Adelaide 5001 South Australia, Australia.

Ph: +61 88302 1536. E:Kate.Kennedy@unisa.edu.au

\section{ABSTRACT}

Background: Many hospitals have implemented COVID-19 risk screening of staff and visitors at point of entry. Little is known about staff perspectives of the screening implementation process.

Aims: To investigate the experiences of staff conducting screening at a metropolitan hospital for a novel virus with constantly evolving messaging and knowledge, and to identify potential improvements to screening procedures.

Methods: An exploratory cross-sectional survey study of 65 nurses who conducted screening at the hospital. The survey contained quantitative and open-ended questions. Descriptive analyses were conducted for quantitative data. Responses from open-ended questions were analysed using thematic analysis.

Findings: Few survey participants (20\%) received training prior to screening and under half (47\%) felt prepared. A majority of participants rated visitors and staff as often or always willing to complete screening questions and have their temperature checked. Approximately half of participants rated their overall experience of screening as positive and most ( $81.5 \%)$ believed the questions were successful in directing at risk people for COVID-19 testing. Themes identified were: hospital environment and screening station setup; necessity for clear information; difficulties and discomfort; and screening is valuable psychologically and for risk reduction.

Discussion: Suggested improvements included training for screening staff, clearly marked screening queues, additional signage explaining requirements, mandatory temperature checking, and separate entry points for staff and visitors.

Conclusion: Participants felt their overall experience of conducting screening was more positive than negative and screening provided positive psychological value for staff and visitors; however, various ways to improve screening processes for staff were identified.

Keywords: SARS-CoV-2, infection control, hospital, screening, nursing.

What is already known about this topic? Physical distancing and infection prevention and control measures contribute to reducing COVID-19 infections, therefore to slow the spread of COVID-19 and ease the impact on health systems, screening of staff and visitors for possible viral exposure prior 
to entry was implemented at healthcare facilities across the world. However, little is known about staff perspectives of the screening implementation process.

\section{What this paper adds:}

Front door screening was perceived to reduce risk and increase public confidence. Nursing staff experiences suggest a need for improvements to the process, such as increased training for staff performing the screening, increased signage and clear screening expectations for visitors prior to reaching screening stations, and changes to screening station set up.

\section{INTRODUCTION}

COVID-19 is an infectious disease caused by SARS-CoV-2 that easily spreads from person to person, primarily through respiratory droplets and aerosols when an infected person coughs, sneezes, or talks. ${ }^{1}$ Healthcare organisations across the world have had to quickly adopt risk mitigation strategies to manage the risk of COVID-19 within their facilities. One such strategy is to screen all people entering the facility, whether this be staff or visitors. Front door screening (FDS) commonly includes a series of questions about the presence of symptoms, recent travel, contact with suspected or confirmed cases of COVID-19, and can also include temperature checks. ${ }^{2-5}$ The primary aim of FDS is to detect individuals with risk factors for COVID-19, and if required, refer them to their doctor, a COVID-19 testing clinic, or an emergency department for testing or care.

Previous research has predominantly investigated the effectiveness of FDS for other outbreaks. ${ }^{2-5}$ Evidence-based on the H1N1 Influenza, Severe Acute Respiratory Syndrome (SARS) and Ebola outbreaks suggested FDS was unlikely to stop the spread of the virus, or pick up those in the early stages of infection, but was likely to be most effective at raising awareness and encouraging people who were symptomatic or had an exposure to stay at home. ${ }^{2-5}$ However, emerging studies based on screening for COVID-19 risk prior to entry at healthcare centres showed it could be useful under certain circumstances. ${ }^{6-8}$ Self-reported symptoms were associated with positive COVID-19 tests in healthcare workers, ${ }^{7}$ and symptom screening had high sensitivity in finding potential COVID-19 cases. ${ }^{6}$ Recent research in an obstetric unit has shown that in low incidence areas, FDS for COVID-19 could be effective at capturing some cases and is more sustainable than nasopharyngeal swabs. ${ }^{8}$

Although these studies provide growing and valuable evidence for the effectiveness of different elements of the FDS process, there is limited research on key stakeholder (e.g. screening staff) perspectives of the implementation of FDS in large tertiary hospitals. Stakeholders are key participants in workplace improvements and engagement with this group is vital to the success of any new program.9,10 Stakeholder perspectives are valuable for identifying barriers to and enablers of successful program implementation, ${ }^{9,11}$ and can assist with streamlining screening processes for current and future epidemics or pandemics. In particular, staff conducting the FDS may have an in-depth knowledge of what was successful about implementation and what could be improved and may provide important contextual information to guide future implementation from their lived experience. ${ }^{11}$

As FDS appears to be a useful tool in the fight to control the spread of infectious diseases like COVID-19, it is reasonable to assume that this strategy will be used again in the future. Therefore, the objective of this study was to explore staff perspectives of implementing FDS in an Australian metropolitan hospital with many entrances, and to identify potential improvements to screening procedures. The study asked the research questions: 1 ) What are the experiences of staff members conducting front door screening? and 2) How can front door screening be improved for staff and visitors?

\section{METHODS}

\section{SETTING}

FDS was conducted at a metropolitan COVID-19 designated hospital in South Australia at the three main hospital entrances between 7am and 9pm, starting from 5 April 2020. A daily count of people screened and those turned away were recorded by FDS staff. People were asked to identify if they were working, attending an appointment, or visiting someone. If they were a visitor, they were asked if they were the designated visitor for the day because visitor caps were in place. The FDS questions were based on information known about the virus at March 2020. These included known local hotspots and health status based on known or suspected symptoms (both updated as needed), and close contact with a confirmed COVID-19 case. An additional question regarding influenza vaccination was added in May based on advice from the Australian Health Protection Principal Committee, and temperature checking was added in June.

\section{OVERVIEW OF THE FDS TRAFFIC}

Over the first three-month period, 194,085 people were screened (daily average 2,231), of these 96,216 were visitors, and 97,869 were staff. People were turned away from entering the hospital $(1,039)$ for the following reasons: 11 were identified as 'high risk' for COVID-19 disease; 164 answered 
'yes' to overseas, interstate, or hotspot travel in the last 14 days; six had close contact with a known case of COVID-19; 437 reported symptoms; 420 were directed to the COVID-19 testing clinic; one was advised to self-isolate.

\section{RECRUITMENT}

An exploratory cross-sectional survey was distributed via email to nurses and nursing assistants who conducted FDS. All health staff performing FDS were eligible to participate. The study was advertised through an internal health area email which contained a link to the survey. To reduce recruitment bias, all 522 staff assigned to FDS stations from commencement of screening to the end of the data collection period were identified. Of these 16 emails were not available; consequently, 506 staff were emailed an invitation to participate. To further ensure all staff were aware of the survey, it was also advertised through an all-staff communication email. Data collection occurred between 7-22 July 2020.

\section{OUTCOME MEASURES}

An anonymous survey was developed by the research team and testing was undertaken both internally by the research team, and colleagues not involved in the project, then externally by three nurse educators at the site. Based on feedback, survey questions were reordered or reworded to reduce potential bias. Thus, survey development was an iterative process. The survey aimed to explore the views and experiences of staff performing FDS to inform potential improvements, and contained binary response questions (yes/no), Likert-type scales, and open-ended survey questions as described below. The survey was administered online using REDCap software, hosted at the University of South Australia. ${ }^{12,13}$

\section{Demographic questions}

Demographic items asked participants their employment role (registered or enrolled nurse, nursing or medical student, other), years working in role (<5years through to $>2$ years), and how many shifts worked at the FDS station ( $<10$ days through to $>40$ days).

\section{Preparation for role}

Participants were asked two binary response questions (yes/ no) about whether they were provided with any training for the FDS process and felt prepared to undertake FDS before they were rostered to their first screening shift (i.e. were they oriented to the purpose of the screening in a way that made them feel confident in explaining it to others). Participants who reported not feeling prepared were further asked an open-ended question about how the preparation of staff for this role could have been improved.

\section{Interactions with visitors and staff}

Participants were asked how often visitors and staff were willing to complete the FDS questions, have their temperature checked, and were accepting of FDS decisions on occasions when they had turned someone away from entering the hospital. Participants were also asked how often they felt uncomfortable due to unpleasant encounters. These questions were asked in relation to three distinct groups: visitors to the hospital; clinical hospital staff and; non-clinical hospital staff. Response options ranged from 1 (Never) to 5 (Always).

\section{Overall experience of FDS and value of temperature checks}

Participants rated their overall experience of conducting screening with each of the three groups on a 5-point Likerttype scale from 1 (Very negative) to 5 (Very positive). They were also asked two binary response questions (yes/no) on whether they think the screening questions were successful in directing people at risk of COVID-19 to the testing clinic and whether temperature checks added value to the FDS process. One open-ended question followed this, asking all participants why they thought temperature checks did or did not add value.

\section{Observations related to screening}

At the end of the survey, two open-ended questions asked participants how they thought the process for screening of staff or visitors could be streamlined or made more efficient, and how they think the process for screening could be improved to better identify staff or visitors who should not be entering the hospital (i.e. potentially infectious cases).

\section{DATA ANALYSIS}

Quantitative survey data were analysed using SPSS $24 .{ }^{14}$ The survey completion rate was 100\% and item-level missing data was minimal on most survey items (ranging from 1.5 to $7.7 \%$ ). Consequently, all participants were retained in the study and analyses used available data. Univariate descriptive analyses were conducted for binary response and Likert-type scales using frequency distributions. 'Not Applicable' responses were defined as missing data and are highlighted in the results. Valid percent for frequency distributions is reported throughout. Open-ended responses were analysed in NVivo 2020 using inductive thematic analysis as described by Braun and Clarke. ${ }^{15,16}$ Thematic analysis included the following steps:1) familiarisation with the data, 2) initial coding, 3) searching for potential themes, 4) reviewing themes and coding, 5) defining themes, and 6) writing the final analysis. The analysis was predominantly conducted by one researcher (DF). Coding and themes were reviewed by a second researcher (JF). Any disagreements were resolved through iterative discussion and revisions. 
Ethical approval was provided by the Central Adelaide Local Health Network (CALHN) HREC (13293), $12^{\text {th }}$ June 2020.

\section{RESULTS}

\section{QUANTITATIVE RESULTS}

\section{Sample}

Of the 506 staff members that were sent the survey over the data collection period, 65 staff completed the survey $(12.8 \%$ response rate). Most participants were registered nurses ( $n=$ $47,72.3 \%$ ), with the remainder employed as enrolled nurses ( $n$ $=13,20 \%)$ or assistants in nursing $(n=5,7.7 \%)$. Just under half ( $n=30,46.2 \%)$ had worked less than five years in their role, while $38.5 \%(n=25)$ had worked five-15 years, and $15.4 \%(n=10)$ had worked more than 16 years in their role.

Since the introduction of FDS, most participants ( $n=60$, 93.8\%) had been allocated to a FDS station for less than ten days, while three ( $4.7 \%$ ) had been allocated to a FDS station between 10-20 days, and one (1.6\%) was allocated for more than 21 days. A minority $(n=13,20.3 \%)$ of participants were provided with training for the FDS process, and under half $(n=31,47.7 \%)$ felt prepared to perform the FDS role (i.e. were oriented to the purpose of FDS and felt confident explaining it to others).

\section{Willingness to comply and acceptance of decisions}

A majority of participants perceived that visitors (75.4\%), clinical staff(61.5\%), and non-clinical staff (69.2\%) were often or always willing to complete FDS questions (see Table 1 ). When asked how often visitors and staff were willing to have their temperature checked, a high proportion of participants selected 'Not Applicable' (N/A): 66.2\% $(n=43)$ selected N/A for visitors, $75.4 \%(n=49)$ selected N/A for non-clinical staff, and $76.9 \%(n=50)$ selected N/A for clinical staff. This is likely due to the later introduction of temperature checking. For those participants who conducted temperature checks, most perceived that visitors ( $85.7 \%$ ) were often or always willing to have their temperature checked, while two-thirds perceived that clinical (64.3\%) and non-clinical staff (66.7\%) were often or always willing to have their temperature checked.

Participants were asked to consider occasions when they had turned someone away from entering the hospital based on FDS, and how often visitors and staff were accepting of why they were turned away (see Table 1 ). A high proportion of participants selected 'Not Applicable' (N/A) in response to survey items regarding acceptance of FDS decisions; 64.6\% ( $n$ $=42)$ selected N/A for clinical staff and $70.8 \%(n=46) \mathrm{N} / \mathrm{A}$ for non-clinical staff, although only $18.5 \%(n=12)$ selected N/A for visitors. Of those participants who had turned someone away, two-thirds perceived that clinical (68.2\%) and non-clinical staff (66.7\%) were often or always accepting of FDS decisions, while one-third of participants perceived that visitors (36.5\%) were often or always accepting.

TABLE 1. WILLINGNESS TO COMPLY WITH SCREENING REQUIREMENTS AND ACCEPTANCE OF SCREENING DECISIONS AMONG VISITORS AND STAFF, AND HOW OFTEN RESPONDENTS FELT UNCOMFORTABLE DUE TO UNPLEASANT ENCOUNTERS WITH VISITORS AND STAFF DURING SCREENING

\begin{tabular}{|c|c|c|c|c|c|c|c|c|c|c|}
\hline \multirow[b]{2}{*}{ Survey item } & \multicolumn{2}{|c|}{ Never } & \multicolumn{2}{|c|}{ Rarely } & \multicolumn{2}{|c|}{ Sometimes } & \multicolumn{2}{|c|}{ Often } & \multicolumn{2}{|c|}{ Always } \\
\hline & n & $(\%)$ & $n$ & (\%) & $n$ & (\%) & n & (\%) & $n$ & (\%) \\
\hline \multicolumn{11}{|c|}{ Willingness to complete screening questions } \\
\hline Visitors & 1 & (1.5) & 3 & $(4.6)$ & 12 & $(18.5)$ & 36 & $(55.4)$ & 13 & $(20.0)$ \\
\hline Clinical staff & 1 & $(1.5)$ & 7 & $(10.8)$ & 17 & $(26.2)$ & 19 & $(29.2)$ & 21 & $(32.3)$ \\
\hline Non-clinical staff & 0 & $(0.0)$ & 10 & $(15.4)$ & 10 & $(15.4)$ & 26 & $(40.0)$ & 19 & $(29.2)$ \\
\hline \multicolumn{11}{|c|}{ Willingness to have temperature checked* } \\
\hline Visitors & 1 & $(4.8)$ & 0 & $(0.0)$ & 2 & (9.5) & 6 & $(28.6)$ & 12 & $(57.1)$ \\
\hline Clinical staff & 1 & (7.1) & 2 & $(14.3)$ & 2 & $(14.3)$ & 4 & $(28.6)$ & 5 & $(35.7)$ \\
\hline Non-clinical staff & 1 & (6.7) & 0 & $(0.0)$ & 4 & $(26.7)$ & 4 & $(26.7)$ & 6 & $(40.0)$ \\
\hline \multicolumn{11}{|c|}{ Acceptance of reason for screening decision* } \\
\hline Visitors & 3 & $(5.8)$ & 14 & $(26.9)$ & 16 & $(30.8)$ & 12 & $(23.1)$ & 7 & (13.5) \\
\hline Clinical staff & 5 & $(22.7)$ & 1 & (4.5) & 1 & $(4.5)$ & 8 & $(36.4)$ & 7 & (31.8) \\
\hline Non-clinical staff & 4 & $(22.2)$ & 1 & $(5.6)$ & 1 & (5.6) & 7 & $(38.9)$ & 5 & $(27.8)$ \\
\hline \multicolumn{11}{|c|}{ Felt uncomfortable due to pleasant encounters } \\
\hline Visitors & 8 & $(12.5)$ & 10 & $(15.6)$ & 34 & $(53.1)$ & 11 & $(17.2)$ & 1 & (1.6) \\
\hline Clinical staff & 28 & $(43.8)$ & 15 & $(23.4)$ & 16 & $(25.0)$ & 5 & $(7.8)$ & 0 & $(0.0)$ \\
\hline Non-clinical staff & 29 & $(45.3)$ & 16 & $(25.0)$ & 13 & $(20.3)$ & 5 & $(7.8)$ & 1 & (1.6) \\
\hline
\end{tabular}

Note. $n=$ number of respondents, $\%=$ valid percent. * $N / A$ responses were excluded. 
TABLE 2. OVERALL EXPERIENCE OF CONDUCTING SCREENING WITH VISITORS AND STAFF

\begin{tabular}{|c|c|c|c|c|c|c|c|c|c|c|}
\hline \multirow[t]{2}{*}{ Group } & \multicolumn{2}{|c|}{ Very negative } & \multicolumn{2}{|c|}{ Negative } & \multicolumn{2}{|c|}{ Neutral } & \multicolumn{2}{|c|}{ Positive } & \multicolumn{2}{|c|}{ Very positive } \\
\hline & $n$ & (\%) & $n$ & (\%) & $n n$ & (\%) & $n$ & (\%) & $n$ & (\%) \\
\hline Visitors & 2 & (3.1) & 13 & $(20.3)$ & 16 & $(25.0)$ & 27 & $(42.2)$ & 6 & (9.4) \\
\hline Clinical staff & 1 & (1.6) & 9 & (14.1) & 19 & $(29.7)$ & 20 & (31.3) & 15 & (23.4) \\
\hline Non-clinical staff & 1 & (1.6) & 8 & (12.9) & 16 & $(25.8)$ & 25 & $(40.3)$ & 12 & (19.4) \\
\hline
\end{tabular}

Note. $\mathrm{n}=$ number of respondents, $\%$ = valid percent.

\section{Experience of staff conducting FDS}

When asked how often they felt uncomfortable due to unpleasant encounters during FDS, over two-thirds of participants reported that they never or rarely felt uncomfortable with clinical (67.2\%) and non-clinical staff (70.3\%), while over two-thirds of participants indicated that they sometimes or often felt uncomfortable with visitors (70.3\%; see Table 1). Over half of participants reported having a positive or very positive overall experience screening visitors (51.6\%), clinical staff(54.7\%), and non-clinical staff(59.7\%; see Table 2).

\section{Success and value of FDS process}

When asked about the success of the FDS process, most participants $(n=53,81.5 \%)$ believed that the screening questions were successful in directing people at risk of COVID-19 to the testing clinic. Moreover, approximately twothirds $(n=37,61.7 \%)$ of participants believed that temperature checks added further value to the screening process.

\section{OPEN-ENDED RESPONSES}

Four themes and one sub-theme were identified through thematic analysis of open-ended survey responses: hospital environment and FDS station setup; necessity for clear information (sub-theme: training processes and support from supervisors); difficulties and discomfort carrying out FDS; and FDS is valuable psychologically and for risk reduction. See Table 3 for quotes associated with the different themes.

\section{Hospital environment and FDS station setup}

A prominent theme in the data was the impact of the hospital layout and environment on the FDS process. The physical layout of the hospital was an issue identified by many participants because it included multiple entrances, not all of which were manned. This was a primary concern because it enabled people to bypass FDS stations. Participants suggested that FDS be done at all doors at all times, or unmanned entrances be locked. Participants suggested separate lines for staff and visitors, distinctively marked queues with physical barriers, security guards, and more FDS staff to address the issue of people simply walking past the FDS station. This was especially needed during times when there was a high flow of people through the main door. Alternatively, one participant suggested that technologies could be implemented for screening, to streamline the process and make it unnecessary for more staff to be assigned to the screening stations.

Many participants felt that staff should not have to participate in FDS, particularly daily, and some suggested that stickers or an express lane could be implemented to bypass or hasten FDS processes for regular staff and visitors. Staff were perceived as already knowing the entry requirements and being expected to follow these, thereby making FDS unnecessary.

Finally, participants highlighted the need for more consistent access to the appropriate supplies and supports, including personal protective equipment and type of thermometers.

\section{Necessity for clear information}

Another prominent theme articulated by most participants was the desire for guidelines and instructions around the FDS process. Both visitors and staff required information to understand expectations and current policies. This was perceived as critical to ensure a smooth screening experience. Participants desired more information at the main entry point (e.g. information boards, signage or handouts) to better inform visitors of the FDS process, help staff enforce policies, and ensure consistency of procedures. Some participants also felt media campaigns to pre-warn the public of hospital requirements would have been helpful.

Staff commonly felt they needed more guidelines and instructions to support their FDS role, provide guidance on how to manage issues that may arise, and clarify the purpose and expectations of the FDS process. Moreover, due to the changing criteria across time as new information about COVID-19 arose and policies were reviewed, guidelines and expectations needed to be regularly updated and distributed to staff. Participants also felt under-informed about managing exemptions to current policies.

\section{Training processes and support from supervisors}

A sub-theme identified within the necessity for clear information was the importance of providing training and induction prior to starting the FDS role. In many cases, participants felt they needed more training, having either had none, or having had information passed on by workers in the previous shift. In contrast, a few participants perceived 
that no training was required for this role as it was a simple process. The lack of training and guidelines for the role, possibly in combination with frequently changing policies, reported as being vague or open to interpretation, appeared to contribute to inconsistencies around role expectations. This had negative consequences for some participants. Finally, some FDS staff felt additional support and availability from senior staff would have improved the experience as expectations and rules often changed between shifts.

\section{Difficulties and discomfort carrying out FDS}

Another theme identified was the negative experiences and feelings of participants related to carrying out FDS processes. Some participants encountered difficulties with carrying out FDS, which impacted their views of the process. For example, some felt the entry requirements were not strict enough, or perceived that people knew about the restrictions, and consequently could lie to screening staff to enter, which made FDS of little use. Some participants felt this increased the value of temperature checking, perceiving it could measure COVID-19 symptoms when people were not honest in answering FDS questions.

Some participants reported staff and visitors behaved unpleasantly or were unaccepting of the requirements. For instance, staff and visitors sometimes refused, ignored or avoided FDS stations, which made the work difficult, stressful, or uncomfortable.

\section{FDS is valuable psychologically and for risk reduction}

Despite the difficulties and negative emotions felt by some participants, other participants perceived that FDS, particularly temperature checking, was valuable psychologically and for risk reduction. Several participants felt that temperature checking increased public confidence in FDS, other participants believed that FDS was useful for highlighting the seriousness of the pandemic and that temperature checking increased the public's confidence in the hospital's response. Many participants felt that temperature checking was necessary as part of successful FDS processes and was useful for clearing visitors, others believed it was useful for identifying risk of infection.

Temperature checking was also valued as a way to collect objective clinical data for documentation purposes and to demonstrate to visitors in a visible way the reason for FDS and possible denial of entry. Several participants noted that FDS and/or temperature checking should have started earlier in the pandemic.

\section{TABLE 3. PARTICIPANT QUOTES RELATING TO THE DIFFERENT THEMES}

\begin{tabular}{|c|c|c|}
\hline Theme & Summary of theme & Quotes \\
\hline $\begin{array}{l}\text { Hospital } \\
\text { environment } \\
\text { and FDS station } \\
\text { setup }\end{array}$ & $\begin{array}{l}\text { The physical layout of } \\
\text { the hospital was an } \\
\text { issue identified by many } \\
\text { participants as it included } \\
\text { multiple entrances, not all } \\
\text { of which were manned. In } \\
\text { addition, during high traffic } \\
\text { periods people were noted } \\
\text { avoiding the screening } \\
\text { stations due to poor visibility } \\
\text { of the stations and queues. } \\
\text { Finally, the accuracy of } \\
\text { the type of thermometers } \\
\text { provided were questioned by } \\
\text { some staff. }\end{array}$ & $\begin{array}{l}\text { "Screening staff is pointless, as they are educated on hospital policy and they can enter } \\
\text { another unmanned door and access the hospital unscreened. i.e. if you take public } \\
\text { transport you get screened but if you drive you don't [carpark entrances were unmanned]." } \\
\text { (P25, Enrolled Nurse). } \\
\text { "Visitors were still getting past staff at the front door. The [hospital] needed designated } \\
\text { lines so people could not get past and maybe security guards to help out. I found the } \\
\text { [hospital] was too casual with their screening and people were just walking into the } \\
\text { hospital without being asked questions or having their temperature checked." (P30, } \\
\text { Enrolled Nurse). } \\
\text { "It could easily be made electronic and then manned by one person. Tick boxes for why } \\
\text { they have come to hospital (ie., visitor, staff, appointment, cafe, parking, etc.), then if they } \\
\text { feel well, then if they have been OS or interstate, or been in contact with COVID cases. } \\
\text { Depending on their answers it could then direct them where they need to go with one } \\
\text { staff member manning it just in case there are questions/uncertainties." (P65, Assistant in } \\
\text { Nursing). } \\
\text { "Staff should be given a sticker to identify them as staff. They should not be getting } \\
\text { screened just because they come through the front door every day. Staff should be } \\
\text { provided with education as to why they should not be coming to work when sick. We } \\
\text { should only be screening visitors." (P39, Registered Nurse). } \\
\text { "It was cold outside because it is winter so checking them as they enter using the forehead } \\
\text { method was not helpful because they read low until the person warmed up enough to get } \\
\text { an accurate reading." (P83, Assistant in Nursing). }\end{array}$ \\
\hline
\end{tabular}


TABLE 3. PARTICIPANT QUOTES RELATING TO THE DIFFERENT THEMES (CONTINUED)

\begin{tabular}{|c|c|c|}
\hline Theme & Summary of theme & Quotes \\
\hline $\begin{array}{l}\text { Necessity for } \\
\text { clear information } \\
\text { (sub-theme: } \\
\text { training } \\
\text { processes and } \\
\text { support from } \\
\text { supervisors) }\end{array}$ & $\begin{array}{l}\text { There was perceived to be a } \\
\text { lack of communication around } \\
\text { the screening stations and } \\
\text { expectations for everyone } \\
\text { involved: staff conducting } \\
\text { screening, other hospital } \\
\text { staff and hospital visitors. A } \\
\text { sub-theme of this was mixed } \\
\text { feelings around consistency } \\
\text { of training for screening staff } \\
\text { and support from supervisors. }\end{array}$ & $\begin{array}{l}\text { "Many had also been given permission by wards to have more than one visitor attend. } \\
\text { One of the patients that arrived was a direct admission with respiratory symptoms, there } \\
\text { was no information provided about what to do with patients who were being admitted } \\
\text { due to chronic respiratory problems, and we were unable to contact the NUM [Nurse Unit } \\
\text { Manager]." (P40, Registered Nurse). } \\
\text { "A group huddle with organiser prior to or at commencement of shift to update role } \\
\text { required." (P26, Registered Nurse) "Especially on weekends, and after hours there were } \\
\text { no clear instructions and unsure if role of nurse was as a health screening role or more } \\
\text { security." (P23, Registered Nurse). "Clear and consistent guidelines for each entry point. } \\
\text { Media exposure to forewarn visitors of what will be occurring." (P34, Registered Nurse). } \\
\text { "...the policy is poorly implemented... and there seems to be no definite 'set of rules' or } \\
\text { guidelines to follow to implement to those visiting nor guidelines to make the public aware } \\
\text { of the changes in regards to visiting the hospital." (P43, Registered Nurse) } \\
\text { Sub theme: } \\
\text { "There was no guidance provided at all and staff had not been made aware they may be } \\
\text { allocated to this role. An email with role guidance or instructions would have been helpful } \\
\text { at the very least". (P47, Registered Nurse). } \\
\text { "It was easy to pick up so training not required." (P2, Registered Nurse). } \\
\text { "I was not given any instructions other than 'ask these questions' by the previous nurses } \\
\text { who had also never done it before and was then told off for not doing the job properly. } \\
\text { Each senior manager gave us different criteria to screen for, ... Then each nurse enforced it } \\
\text { to their desire which made things even harder. It wasn't a pleasant experience at all." (P3, } \\
\text { Registered Nurse). } \\
\text { "Senior point of contact who was available throughout the screening period to assist } \\
\text { when required. ... Someone managing the screening and available as a contact for difficult } \\
\text { encounters." (P34, Registered Nurse). }\end{array}$ \\
\hline $\begin{array}{l}\text { Difficulties and } \\
\text { discomfort } \\
\text { carrying out FDS }\end{array}$ & $\begin{array}{l}\text { There were some discomforts } \\
\text { in carrying out FDS, with } \\
\text { some staff and visitors } \\
\text { refusing to be screened, } \\
\text { slipping past the screening } \\
\text { stations, or lying about their } \\
\text { personal risk status in order } \\
\text { to enter. }\end{array}$ & $\begin{array}{l}\text { "There needed to be protocols and the checks needed to be more mandatory. Every } \\
\text { other hospital... were much stricter in their screening for entering the hospital than [our } \\
\text { hospital], which was the COVID-19 main hospital." (P30, Enrolled Nurse). } \\
\text { "The people that did stop said no before questions were even asked. Everyone that was } \\
\text { questioned knew about COVID and its restrictions; therefore anyone that had made the } \\
\text { effort to come into hospital would have said whatever they needed to to [sic] enter." (P1, } \\
\text { Registered Nurse). } \\
\text { "People can give you false information whereas checking temperatures can perhaps capture } \\
\text { someone that is unwell and should not be entering the hospital but staying home." (P37, } \\
\text { Enrolled Nurse). } \\
\text { "Lots of staff in particular were very rude about getting screened. 'I wouldn't be at work } \\
\text { if I was sick would I?' type of comments were often made or staff would often walk past } \\
\text { quickly and avoid eye contact as to not be screened, making it difficult for visitors as } \\
\text { they would say 'well that person just walked past why do I need to be screened'." (P35, } \\
\text { Registered Nurse). }\end{array}$ \\
\hline $\begin{array}{l}\text { FDS is valuable } \\
\text { psychologically } \\
\text { and for risk } \\
\text { reduction }\end{array}$ & $\begin{array}{l}\text { FDS, particularly temperature } \\
\text { checking, was perceived to } \\
\text { be valuable psychologically; } \\
\text { FDS reassured both staff } \\
\text { and visitors that the hospital } \\
\text { was showing due care. FDS } \\
\text { was also perceived to reduce } \\
\text { risk by halting entry for } \\
\text { those in high risk groups and } \\
\text { highlighting the need to stay } \\
\text { home if unwell. }\end{array}$ & $\begin{array}{l}\text { "People felt confident knowing their temp was taken as precaution \& were interested in it } \\
\text { being taken." (P28, Registered Nurse). } \\
\text { "I think it provided a sense of a coordinated effort on behalf of the hospital to keep people } \\
\text { 'safe'." (P33, Registered Nurse). } \\
\text { "It was one measurable way to clear visitors to the hoslital [sic]." (P6, Registered Nurse). } \\
\text { "It is important to identify people who might already have the COVID infection as not } \\
\text { to spread it to already at risk and immunocompromised people in the hospital." (P19, } \\
\text { Registered Nurse). } \\
\text { "We didn't do temp checks... but I think it would be useful as the general person doesn't } \\
\text { check or own thermometer at home. Also when staff arrived with sore throat etc. having } \\
\text { temp check at the door would have stopped them going up to their ward to talk to their } \\
\text { NUM [Nurse Unit Manager]." (P15, Registered Nurse). } \\
\text { "If someone had a cough } \backslash \text { flu like symptoms and showed a high temp it was something } \\
\text { tangible the person could see for themselves and shed some more light on the reason for } \\
\text { the screening process." (P41, Registered Nurse) } \\
\text { "Needed to have temperature screening sooner." (P35, Registered Nurse). }\end{array}$ \\
\hline
\end{tabular}




\section{DISCUSSION}

The survey provided insight into the experiences of staff conducting FDS, and their suggestions for how the process could be improved. The staff conducting FDS reported that most visitors and staff were often or always willing to comply with FDS questions and temperature checks. However, visitors were less frequently rated as being often or always accepting of why they were turned away than staff. Most screening staff reported unpleasant encounters with visitors sometimes or often, and with clinical or non-clinical staff never or rarely. However, the open-ended responses provide a slightly different perspective with many participants highlighting negative incidents with staff rather than those with visitors. It is possible the unpleasant encounters with visitors reported by the survey participants may have stemmed from being turned away due to hospital-instituted caps on the number of visitors a patient could have each day. However, while visitors may have actually been less often accepting of being turned away as reflected in the quantitative results it is possible that unpleasant encounters from colleagues were more memorable than those with a stranger one is unlikely to see again, hence the emphasis on unpleasant staff encounters in the open-ended responses.

A high proportion of participants selected 'Not Applicable' in response to survey items regarding acceptance of screening decisions, indicating most participants had not turned away staff based on FDS but had turned away visitors, which is likely because staff were aware of current FDS practices in their workplace and because limits on visitors per patient did not affect staff. There was also perceived to be a shortage of information to inform visitors of the expectations around FDS, and many suggested greater communications to the general public about the need for and importance of FDS. Only a minority of participants reported receiving training to undertake FDS, and less than half felt prepared for the role leading to suggested improvements in guidance for FDS staff about current policy, as this was reported to change between shifts. The combination of constantly changing information due to the nature of the COVID-19 pandemic and the resulting changes in hospital policy was a source of frustration for survey respondents. Research prior to the COVID-19 pandemic had shown that constant change can lead to negative impacts on staff, ${ }^{18}$ potentially increasing disengagement and apathy to the change and failure to express discontent. ${ }^{19}$ Workplaces with greater professional autonomy, greater control over the practice environment, and the use of systems that promote accountability and continuity of care can mitigate negative effects, suggesting greater communication and involvement in policy changes relevant to FDS may be an important protective factor. ${ }^{19}$

Participants held mixed views on the value of temperature checks. While two-thirds indicated temperature checks added value, and most visitors were willing to have their temperature taken, participants raised that mandatory temperature checks escalated negativity and unwillingness to be screened, particularly among staff. They also noted temperature checks were time consuming and difficult to manage during peak visiting hours, and did not take into account that high temperatures may be the result of other health issues, and low temperatures could be the result of winter weather or the general inaccuracies inherent in forehead thermometers. These participants indicated in-ear thermometers would have been more accurate. However, staff also perceived that the temperature checks were more accurate than self-reported symptoms, provided an objective measurement that was seen to facilitate compliance, and promoted a sense of a coordinated effort from the hospital to keep people safe, providing psychological reassurance to the general public, and to staff. This mix of perspectives has been reflected in the wider literature which indicated temperature checking in epidemics or pandemics provides psychological benefits more than accurate capture of those infected. ${ }^{2,3,8}$

There were dissenting opinions regarding FDS requirements for staff. While some participants felt strongly that staff should not be exempt from screening, many believed staff should not be screened daily, and some suggested a temperature check alone would suffice. Reported issues pertaining to staff screening included that staff were aware of hospital policy and how to answer questions correctly, could choose to enter via unmanned doors if desired, and were known to ignore or bypass FDS stations. The emergence of new apps and symptom trackers for health workers could be one way to address some of the issues reported in regard to screening staff. ${ }^{17}$

\section{IMPLICATIONS FOR FUTURE PRACTICE}

This study provides possible suggestions for the improvement of future FDS processes, including having well-marked and equipped screening stations, providing information for staff and visitors around policies and expectations, and considering the intended purposes of FDS when choosing setup and screening elements. Further investigation of the value of screening clinical and nonclinical staff, and the possible methods to streamline the process (eg. use of technology) is required.

\section{LIMITATIONS}

The main limitation of this study was the very low number of COVID-19 cases in South Australia. Another limitation was the porous nature of the hospital with multiple entrances. It was not possible (due to both cost and staff numbers required) to either close or set up a FDS station at every entrance. Finally, this was a very small sample of the people involved in FDS at a single institution. The response rate of $12.5 \%$ was very low suggesting that this may not be a representative sample of the FDS staff. Low response rates to surveys are not uncommon in health professionals who often cite lack of time, lack of interest in research, or survey fatigue as reasons 
for not responding. ${ }^{19,20}$ It is possible that those who answered the survey were the staff who felt strongly about various aspects of the process, consequently generalisation to other institutions or settings should be made with caution. Despite these limitations, a strength of this study was the inclusion of closed and open-ended questions, which provided participants an opportunity to share their thoughts on possible improvements to current or future FDS processes, and allowed a more detailed exploration of the screening implementation process.

\section{CONCLUSION}

FDS staff believed the screening was successful in directing people at risk of COVID-19 to the testing clinic and noted the positive psychological value of temperature checking. Moreover, most participants rated their overall experience of conducting FDS with visitors and staff as more positive than negative, although this was closer to neutral for visitors. Key suggestions for improvement by FDS staff were: training and instruction of FDS staff prior to their first shift, structured communication between shifts, clearly marked queues with distance markers on the floor and barriers, additional signage and other forms of information explaining the requirements, mandatory temperature checking, and separate entry points for staff and visitors.

Acknowledgements: We would like to thank the CALHN team, Kathryn Zeitz, Gerry O'Callaghan, Rebecca Badcock, Rebecca Munt, Michelle Cunnew, Craig Robinson and Christina Isaksson, who supported the data collection and provided us with the necessary documentation to inform this research. We also thank Micah Peters, Greg Sharplin, Rebecca Munt and Marion Eckert as the research team involved in the study that informed this paper.

Funding: This study was supported by The Hospital Research Foundation, South Australia. They were not involved in the analysis or interpretation of the data nor the submission of the results.

Conflict of interest: We the authors state that we have no financial or other conflict of interest related to this publication or the outcomes of this research.

\section{REFERENCES}

1. Centre for Disease Control and Prevention (CDC). Coronavirus Disease 2019 (COVID-19): How does the virus spread? USA. 2020 [cited 2020 Oct 15]. Available from: https://www.cdc.gov/coronavirus/2019-ncov/faq.html\#Spread

2. Gostic K, Gomez AC, Mummah RO, Kucharski AJ, Lloyd-Smith JO. Estimated effectiveness of symptom and risk screening to prevent the spread of COVID-19. Elife. 2020;9:e55570.

3. Normile D. Why airport screening won't stop the spread of coronavirus. Science. 2020. [cited 2020 Oct 15] Available from: https://doi.org/10.1126/science.abb6136
4. Mouchtouri VA, Christoforidou EP, Heiden MA, Menel Lemos C, Fanos $M$, Rexroth $U$, et al. Exit and entry screening practices for infectious diseases among travelers at points of entry: Looking for evidence on public health impact. Int J Environ Res Public Health. 2019;16(23):4638.

5. Wilder-Smith A, Chiew CJ, Lee VJ. Can we contain the COVID-19 outbreak with the same measures as for SARS? Lancet Infect Dis. 2020;20(5):E105-E107

6. Clemency BM, Varughese R, Scheafer DK, Ludwig B, Welch JV, McCormack RF, et al. Symptom criteria for COVID-19 testing of heath care workers. Acad Emerg Med. 2020;27(6):469-74.

7. Lan FY, Filler R, Mathew S, Buley J, Lliaki E, Bruno-Murtha LA, et al. COVID-19 symptoms predictive of healthcare workers' SARS-CoV-2 PCR results. PloS one. 2020;15(6):e0235460.

8. Tassis B, Lunghi G, Frattaruolo MP, Ruggiero M, Somigliana E, Ferrazzi E. Effectiveness of a COVID-19 screening questionnaire for pregnant women at admission to an obstetric unit in Milan. Int J Gynaecol Obstet. 2020;150(1):124-6

9. Griffiths J, Maggs H, George E. Stakeholder involvement: a background paper prepared for the WHO/WEF joint event on preventing noncommunicable diseases in the workplace (Dalian/China, September 2007). World Health Organization. Switzerland. 2008. [cited 2020 Oct 15] Available from: https://www.who.int/dietphysicalactivity/griffiths-stakeholderinvolvement.pdf

10. Bauer MS, Kirchner J. Implementation science: what is it and why should I care? Psychiatry Res. 2020;283:112376.

11. Horev T, Babad YM. Healthcare reform implementation: stakeholders and their roles - the Israeli experience. Health Policy. 2005;71(1):1-21.

12. Harris PA, Taylor R, Minor BL, Elliott V, Fernandez M, O'Neal $L$, et al. The REDCap consortium: building an international community of software platform partners. J Biomed Inform. 2019;95:103208.

13. Harris PA, Taylor R, Thielke R, Payne J, Gonzalez N, Conde JG. Research electronic data capture (REDCap) — a metadata-driven methodology and workflow process for providing translational research informatics support. J Biomed Inform. 2009;42(2): 377-381.

14. Statistical Package for Social Sciences. IBM. Version 24, 2019.

15. NVIVO qualitative data analysis software. QSR International Pty Ltd. Version 12, 2020.

16. Braun V, Clarke V. Using thematic analysis in psychology. Qual Res Psychol. 2006;3(2):77-101.

17. Ranosa R. COVID-19: 6 apps to monitor employee health. Human Resources Director. Human Resources Director. 2020. [cited 2021 Feb 8] Available from: https://www.hcamag.com/ us/specialization/hr-technology/covid-19-6-apps-to-monitoremployee-health/220371.

18. Brown R, Wey H, Foland K. The Relationship Among Change Fatigue, Resilience, and Job Satisfaction of Hospital Staff Nurses. J Nurs Scholarsh. 2018;50(3):306-13

19. McMillan K, Perron A. Change fatigue in nurses: a qualitative study. J Adv Nurs. 2020;76(10):2627-36.

20. Cooper AL, Brown J. Maximising nurses' and midwives' response rates to surveys. Nurse Res. 2017;25(3):31. 